\title{
ICT Use in Family Caregiving of Elderly and Disabled Subjects
}

\author{
Mia Hautala ${ }^{1,2}$, Niina S. Keränen ${ }^{1,2}$, Eeva Leinonen ${ }^{3}$, Maarit Kangas ${ }^{1,2}$, and Timo \\ Jämsä $\ddot{1}^{1,2,4}$ \\ ${ }^{1}$ Research Unit of Medical Imaging, Physics and Technology (MIPT), University of Oulu, \\ ${ }^{2}$ Medical Research Center (MRC), Oulu University Hospital and University of Oulu, \\ ${ }^{3}$ Faculty of Information Technology and Electrical Engineering, University of Oulu, and \\ ${ }^{4}$ Department of Diagnostic Radiology, Oulu University Hospital. \\ \{mia.hautala, niina.s.keranen, eeva.leinonen. maarit.kangas, timo.jamsa\}@oulu.fi
}

\begin{abstract}
This study examined the use of ICT in caregiving as assessed by family caregivers of disabled or elderly subjects $(\mathrm{N}=53)$. The results showed limited current use of ICT-based technologies either for on-site or remote assistance. However, perceived usefulness was evaluated as high when these technologies were used. The factors for the use of ICT were different for on-site assistance or remote assistance. The data obtained can be used in the development of future ICT and IoT -based assistive technologies.
\end{abstract}

Keywords: Caregiver, assistive technology, remote care, eHealth, ICT, IoT.

\section{Introduction}

Persons with disabilities use assistive technology to increase, maintain, or improve their functionality and performance in daily tasks and activities. Assistive technology can be a service, device, application or tool that helps the elderly, disabled person or their caregiver to maintain functional ability of the care recipient [1], [2], [3]. Assistive technology can consist e.g. of mechanical and electrical devices, sensors, IoT applications, and cloud services. Assistive technologies have been found to have ability to improve user's activity and participation, and also to reduce the functional decline of the user [2], [4], [5].

Assistive technologies can also be seen as a solution to reduce caregiver's burden. ICT devices and applications can decrease the demands related to care and supervision of the care recipient. In addition, those can be used to monitor any unexpected needs of assistance, i.e. accidents and injuries [2], [6]. Caregivers, either family members or others who provide care for those who need supervision or assistance in illness or disability [7], are seen as a valuable resource for elderly care in their unpaid contribution for the ageing society [8].

ICT and IoT solutions might be increasingly valuable in assisting elderly and disabled persons in future. The aim of this study was to examine to what extent the family caregivers utilize ICT-based assistive technologies in their caregiving work, and what are the needs for and perceived usefulness of assistive technologies. 


\section{Materials and Methods}

An online survey was implemented through the Finnish Society for Caregivers (Omaishoitajat ry) webpage. The survey was open for responses from September 30th to October 25th 2015 and at the same time it was advertised through social media as well. A pilot survey was carried out with two caregivers and one researcher before the implementation. The caregiver answered both to the questions for him/herself and to the questions related to the care recipient.

The survey consisted of five main categories: Background, Assistive technologies and tools, Time utilization, Burden, and Coping. The response to the questions related to Assistive technologies and tools are presented in this paper (Table 1).

Table 1. Questions related to background information and assistive technology and tools.

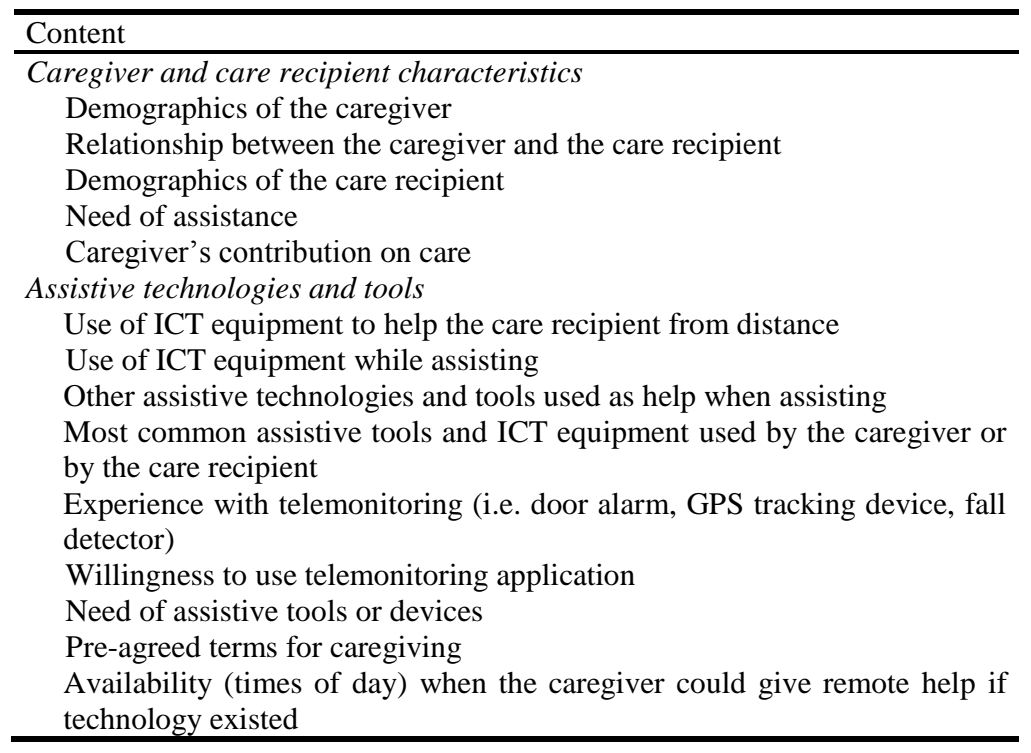

The survey contained both qualitative and quantitative questions. Qualitative methods were used for questions about assistive tools and ICT equipment to collect information about the needs and expectations assigned for the technology.

Five-point Likert scale was used to score the perceived usefulness of assistive tools and ICT equipment as a Perceived Usefulness Score (PUS), 1 referring to Never, 2 to Rarely, 3 to Sometimes, 4 to Quite Frequently and 5 to Nearly always. The respondent was allowed to list and score a maximum of 5 tools or equipment for evaluation.

Results are expressed as mean \pm standard deviation (SD). Statistical analysis were performed in IBM SPSS 22. 


\section{Results}

In total there were 53 caregiver respondents, mostly female $(n=46)$, with average age of 54.3 years. Characteristics of the caregivers and care recipients are presented in Table 2. There were 31 male and 22 female care recipients with an average age of 48.7 years. Most of the care recipients lived with the caregiver and only three of them lived alone. Forty-seven of the caregivers had made informal care agreement. Seventy percent of the care recipients needed assistance around the clock and $26 \%$ daily. Assistance was also needed when moving outdoors or indoors. Caregiver's contribution on care were typically between 81 and $100 \%$ of the total care need.

Table 2. Characteristics of the caregiver and care recipient $(\mathrm{N}=53) . \mathrm{N}(\%)$ if not otherwise stated.

\begin{tabular}{ll}
\hline Characteristics & \\
\hline Demographics of the caregivers & \\
Age \pm SD (range) (years) & $54.3 \pm 13.5(27-82)$ \\
Female & $46(87 \%)$ \\
$\quad$ Caregiver agreement & $47(89 \%)$ \\
Relationship to care recipient & \\
Spouse & $25(47 \%)$ \\
Parent & $20(38 \%)$ \\
(Grand-) Children & $7(13 \%)$ \\
Demographics of the care recipients & \\
Age \pm SD (range) (years) & $48.7 \pm 29.9(3-92)$ \\
Female & $22(42 \%)$ \\
Living alone & $3(6 \%)$ \\
Living with caregiver & $49(92 \%)$ \\
Need of assistance & \\
Around the clock & $37(70 \%)$ \\
Daily & $14(26 \%)$ \\
When moving outdoors & $48(91 \%)$ \\
When moving indoors & $39(74 \%)$ \\
Caregiver's contribution on care & \\
81-100\% of total care need & $35(66 \%)$ \\
61-80\% of total care need & $10(19 \%)$ \\
41-60\% of total care need & $6(11 \%)$ \\
20-40\% of total care need & $2(4 \%)$ \\
\hline SD standard deviation &
\end{tabular}

SD standard deviation

The care recipients had also need for help in bathing (53 respondents; 100\%), using the toilet $(48 ; 91 \%)$, getting dressed $(53 ; 100 \%)$, cooking $(53 ; 100 \%)$, and keeping contacts (e.g. using telephone or computer) $(49 ; 92 \%)$. Caregivers mentioned that care recipients may also need help with medication $(48 ; 91 \%)$, daily chores $(24 ; 45 \%)$, eating $(43 ; 81 \%)$, hobbies or school $(38 ; 72 \%)$, communicating, or in social situations $(32 ; 60 \%)$.

Fifteen $(28 \%)$ of the respondents used ICT equipment to help care recipient from distance (teleassistance), whereas $12(23 \%)$ had used ICT equipment when assisting on-site. Tablets and other devices with internet access had been used to search 
information, to study (e.g. Papunet, papunet.net), to stay in touch with friends and relatives, and to support and learn communication skills (e.g. DialoQ, www.dialoq.com).

Caregivers had also used other assistive technologies and tools when assisting. Wheelchair was mentioned as the most used when asked for listing five most common technologies (Table 3). Perceived usefulness as scored by the caregivers ranged from 5.0 to 3.6 (scale 1-5) for different assistive tools and equipment.

Table 3. Most common assistive tools and ICT equipment listed by the caregivers and the Perceived Usefulness Scores (PUS). (Open question, $\mathrm{N}=53$ )

\begin{tabular}{lcc}
\hline Tools & N & PUS \\
\hline Wheelchair / Stroller & 16 & 4.9 \\
Lifting device / subsidies & 12 & 4.5 \\
Computer / Tablet & 11 & 4.2 \\
Hospital bed & 10 & 4.9 \\
Mobile phone / Security phone & 10 & 4.2 \\
Washing / Shower chair & 9 & 4.7 \\
Rollator & 6 & 3.6 \\
Toilet rack & 5 & 5.0 \\
Electric / Bedsore mattress & 4 & 4.9 \\
\hline
\end{tabular}

Eight caregivers $(15 \%)$ had some experience with telemonitoring their care recipient (i.e. door alarm, GPS tracking device, fall detector). Additional 14 (26\%) would be willing to use telemonitoring applications. Personal emergency response systems, fall detectors, security phones, baby monitors, motion sensors and radar light had been used so far. GPS tracking devices, door alarms and security or web cameras seemed to be most requested in future.

Thirty-four $(64 \%)$ of the caregivers were unwilling to use telemonitoring applications because they felt there was no need, such applications would not help them, they were not familiar with the applications, or the care recipient needed caregiver's physical presence.

From the respondents seven (13\%) had a pre-agreed terms about caregiving, for example about allowing care recipient to do as much as possible on his/her own and assisting only when needed. Also there were terms about the responsibilities, such as who will take care of finances, groceries and medication. Occasionally terms and assistance were dependent on the schedules. Table 4 presents the times of day when the caregivers could help their care recipient from distance, assuming that suitable technology existed.

Table 4. Times of day for the availability of the caregiver for teleassistance (i.e. by computer or phone) if the technology existed $(\mathrm{N}=23)$.

\begin{tabular}{lcccccccc}
\hline \multicolumn{1}{c}{ Hours } & $6-9$ & $9-12$ & $12-15$ & $15-18$ & $18-21$ & $21-24$ & $24-3$ & $3-6$ \\
\hline Available & $78 \%$ & $78 \%$ & $78 \%$ & $87 \%$ & $100 \%$ & $87 \%$ & $74 \%$ & $74 \%$ \\
$\begin{array}{l}\text { Limited } \\
\text { availability }\end{array}$ & $17 \%$ & $4 \%$ & $4 \%$ & $4 \%$ & $0 \%$ & $9 \%$ & $4 \%$ & $4 \%$ \\
Not available & $4 \%$ & $13 \%$ & $13 \%$ & $9 \%$ & $0 \%$ & $0 \%$ & $17 \%$ & $17 \%$ \\
\hline
\end{tabular}


Table 5 presents factors related to ICT use in on-site and remote caregiving. The factors partly differed between on-site assistance and remote assistance. E.g. physical disability and mid-age of the care recipient were related with increased use of teleassistance.

Table 5. Factors related to ICT use in on-site and remote caregiving.

\begin{tabular}{|c|c|c|c|}
\hline Factors & $\mathrm{N}$ & $\begin{array}{l}\text { Have used ICT while } \\
\text { assisting on-site }\end{array}$ & $\begin{array}{l}\text { Have used ICT for } \\
\text { teleassistance }\end{array}$ \\
\hline \multicolumn{4}{|l|}{ Caregiver's age (years) } \\
\hline $30-39$ & 7 & $17 \%$ & $7 \%$ \\
\hline $40-49$ & 13 & $8 \%$ & $33 \%$ \\
\hline $50-59$ & 11 & $33 \%$ & $33 \%$ \\
\hline $60-69$ & 15 & $25 \%$ & $27 \%$ \\
\hline $70-79$ & 5 & $17 \%$ & $0 \%$ \\
\hline $80-$ & 1 & $0 \%$ & $0 \%$ \\
\hline \multicolumn{4}{|l|}{ Care recipient's age } \\
\hline $1-9$ & 7 & $33 \%$ & $33 \%$ \\
\hline $10-29$ & 11 & $33 \%$ & $17 \%$ \\
\hline $30-49$ & 7 & $0 \%$ & $43 \%$ \\
\hline $50-69$ & 12 & $25 \%$ & $33 \%$ \\
\hline $70-89$ & 12 & $25 \%$ & $0 \%$ \\
\hline $90-100$ & 4 & $0 \%$ & $0 \%$ \\
\hline \multicolumn{4}{|l|}{ Primary disability } \\
\hline Memory Disorder & 12 & $23 \%$ & $23 \%$ \\
\hline Mental retardation & 9 & $40 \%$ & $10 \%$ \\
\hline Old age & 1 & $0 \%$ & $0 \%$ \\
\hline Physical disability & 6 & $0 \%$ & $57 \%$ \\
\hline Parkinson's disease & 3 & $17 \%$ & $0 \%$ \\
\hline Brain injury & 5 & $33 \%$ & $17 \%$ \\
\hline \multicolumn{4}{|l|}{ Need of assistance } \\
\hline Several days (4-6) in a week & 2 & $0 \%$ & $50 \%$ \\
\hline Daily & 14 & $7 \%$ & $50 \%$ \\
\hline Around the clock & 37 & $30 \%$ & $19 \%$ \\
\hline \multicolumn{4}{|c|}{ Caregiver's contribution on the care } \\
\hline $20-40 \%$ & 2 & $0 \%$ & $50 \%$ \\
\hline $41-60 \%$ & 6 & $33 \%$ & $33 \%$ \\
\hline $61-80 \%$ & 10 & $0 \%$ & $60 \%$ \\
\hline $81-100 \%$ & 35 & $29 \%$ & $17 \%$ \\
\hline \multicolumn{4}{|l|}{ Another work of the caregiver } \\
\hline Has other work & 19 & $21 \%$ & $42 \%$ \\
\hline Has no other work & 34 & $24 \%$ & $21 \%$ \\
\hline
\end{tabular}

\section{Discussion}

This survey presented limited current use of ICT of assistive technologies by family caregivers of disabled or elderly subjects. However, perceived usefulness was 
evaluated as high when these technologies were used. Additionally, there was some willingness to use assistive technologies if those existed or were available. The factors for the use of ICT were partly different for on-site assistance or remote assistance, e.g. physical disability and mid-age of the care recipient being related with increased use of teleassistance. The data obtained can be used in the development of future ICT and IoT -based assistive technologies.

Acknowledgments. The authors acknowledge the persons participating in the survey, and the Finnish Society for Caregivers (Omaishoitajat ry) for their help. Dr. Jorma Riihijärvi is acknowledged for statistical analyses. The study was supported by the ASTS (Assistive Technologies for Seniors, Teleassistance for seniors with Dementia - A Novel Concept for Safety) joint project by Academy of Finland (grant nr 270816) and Japan Science and Technology Agency; the iKaaS joint project by the European Union (grant $\mathrm{nr}$ 643262) and the Ministry of Internal Affairs and Communication, Japan; Infotech Oulu; and the Finnish Cultural Foundation.

\section{References}

1. McKeon H.P. Assistive Technology Act of 2004 (2004)

2. Mortenson W.B., Demers L., Fuhrer M.J., Jutai J.W., Lenker J., DeRuyter F.: Development and preliminary evaluation of the caregiver assistive technology outcome measure. J Rehabil Med (2015)

3. Administration on Aging. Assistive Technology. Fact Sheet. U.S. Department of Health and Human Services (2003)

4. Wilson D.J., Mitchell J.M., Kemp B.J., Adkins R.H., Mann W.: Effects of assistive technology on functional decline in people aging with a disability. Assist Technol (2009)

5. Salminen A.L., Brandt Å., Samuelsson K., Töytäri O., Malmivaara A.: Mobility devices to promote activity and participation: a systematic review. J Rehabil Med (2009)

6. Aloulou H., Mokhtari M., Tiberghien T., Biswas J., Phua C., Lin J., Yap P.: Deployment of assistive living technology in a nursing home environment: methods and lessons learned. BMC Medical Informatics and Decision Making (2013)

7. National Center for Biotechnology Information. MESH-term: Caregiver, http://www.ncbi.nlm.nih.gov/mesh/ 68017028

8. Feinberg L., Reinhard S.C., Houser A., Choula R.: Valuing the invaluable: the growing contributions and costs of family caregiving (2011 update). Washington: American Association of Retired Persons (2011) 